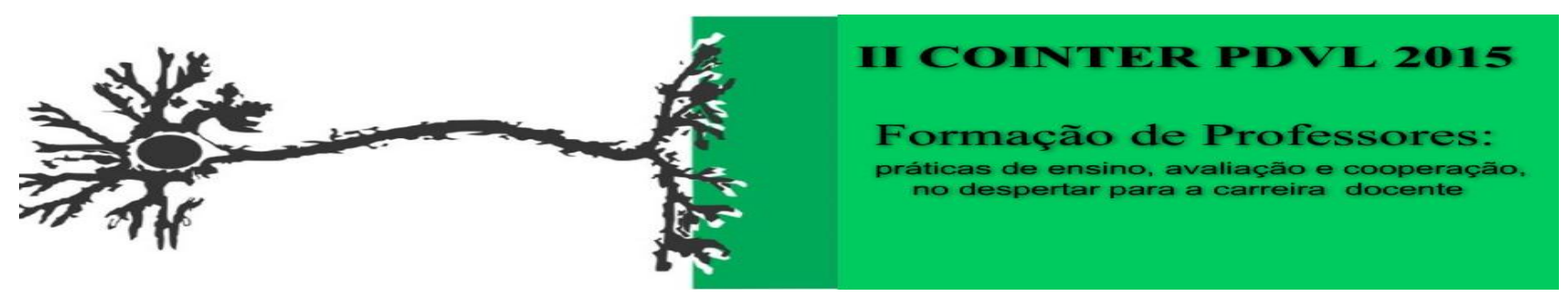

\title{
A EXPLORAÇAO DO CONCEITO DE URBANIZAÇÃO NAS TURMAS DE ENSINO MÉDIO NA ESCOLA ESTADUAL PROFESSOR ANTONIO PINTO DE MEDEIROS- NATAL,RN,PELO PIBID GEOGRAFIA DO IFRN.
}

\author{
Apresentação: Relato de Experiência \\ Marcelo Farias de frança ${ }^{1}$;Sandrielly do Prado Juvencio ${ }^{2}$; Keylla Teixeira Fernandes ${ }^{3}$; Levi \\ Rodrigues de Miranda ${ }^{4}$;
}

\section{Introdução}

O presente trabalho foi desenvolvido a partir das experiências vivenciadas em várias turmas do ensino médio da E. E. Antônio Pinto no ano de 2014, em Natal/RN na execução do projeto realizado pelo PIBID que tem como intuito de auxiliar com atividades diferenciadas que venham a contribuir no processo de aprendizado.

No decorrer deste trabalho é relatado o desenvolvimento das atividades, envolvendo a abordagem do conceito de urbanização, de forma que os alunos perceberam através do desenvolvimento da atividade, a importância desse conteúdo, e o papel que a urbanização desempenha em nossas vidas, pois a geografia escolar tem o objetivo de formar cidadãos conscientes do espaço em que estão inseridos.

\section{Relato de Experiência}

A execução desta atividade didático-pedagógica com $2^{\circ}$ ano do curso médio, parte de uma perspectiva na busca de trabalhar o processo de urbanização desde sua manifestação até os dias atuais na cidade do Natal/RN, partindo do conceito de urbanização em diferentes esferas e correntes de pensamentos, buscando sempre levar os alunos do entenderem como se deu o processo de urbanização na cidade em que eles moram.

A primeira etapa do processo foi à pesquisa exploratória para elaboração das aulas teóricas que fundamentariam nossa explicação, buscando sempre relacionar os conteúdos ministrados em

\footnotetext{
${ }^{1}$ Licenciatura em geografia,IFRN,marcelo.franca.2012@hotmail.com

${ }^{2}$ Licenciatura em geografia, IFRN,sandrielly.juvencio@hotmail.com

${ }^{3}$ Licenciatura em geografia,IFRN,keylla_tf@hotmail.com

${ }^{4}$ Geografo, Mestre em arquitetura e urbanismo, docente IFRN,levi.miranda@ifrn.edu.br
} 
sala de aula com o cotidiano dos alunos, pois como diz a teoria de Ausubel (AUSUBEL, 1969; MOREIRA, 1983), para que haja essa assimilação significativa do novo conteúdo, é necessário que exista na estrutura cognitiva qual o novo conceito se ligue de forma significativa, os subsunçores. Assim, para execução da aula utilizamos alguns recursos didáticos, como o Projetor, Computador, para auxiliar.

O segundo momento, foi o lançamento de uma proposta de atividade que levaria os alunos a mostrarem o que eles haviam entendido através das imagens vistas, pois a prática da leitura e interpretação das imagens seria como um facilitador da aprendizagem do aluno. Quando se vê uma imagem, uma série de relações pode ser feitas com as mais diferentes informações que graças às experiências de vida do aluno que foram acumuladas na mente. Desta forma, os alunos fizeram desenhos em TNT com lápis grafite e segundamente coloriram o desenho que representava a urbanização com lápis de cor. No terceiro memento as atividades foram apresentadas, para discussão coletiva onde podemos constatar que a metodologia de estudo aplicada com os alunos fez com que os mesmos aprendessem o conteúdo de formas diferenciadas, com uma abordagem crítica sobre o processo de urbanização.

\section{Considerações}

Mediante a metodologia de estudos apresentada, levando-se em consideração as experiências vivenciadas, apontando-se possibilidades de outras propostas futuras. Neste momento são relacionadas às diversas ideias desenvolvidas ao longo do trabalho, num processo de síntese dos principais aspectos vivenciados, com os comentários do autor e as contribuições trazidas pela experiência.

\section{Referências}

AUSUBEL, D. P.; Novak, J. D.; Hanesian, J. Psicologia educacional. Rio de Janeiro: Interamericana, 1980.

RIO GRANDE DO NORTE. Instituto Federal de Educação, Ciência e Tecnologia do. Programa Institucional de Bolsa de Iniciação à Docência - PIBID: detalhamento do SUBPROJETO (Licenciatura em Geografia) / Levi Rodrigues de Miranda (coordenador). Natal: CAPES / IFRN,2011. 
